\title{
From Starbucks to Carrefour: Consumer Boycotts, Nationalism and Taste in Contemporary China
}

\author{
Nyíri Pál, Vrije Universiteit Amsterdam, the Netherlands
}

In April 2008, the worldwide 'relay' of the torch that was to light the flame at the Beijing Olympics was accompanied by widely publicised protests by human-rights activists wishing to draw attention to the plight of Tibetans. These, in turn, triggered larger-scale counterprotests by Chinese students indignant at what they saw as attempts, condoned by biased Western media and the tacit approval of Western governments, to deny China its well-deserved recognition. In Paris, they felt particularly unwelcome: a Tibetan protester tried to snatch the torch from a Chinese paralympic fencer, Jin Jing, and a banner supporting human rights was hung from the city hall, prompting Chinese officials to cancel a planned reception. Chinese-language Internet bulletin boards (BBS), discussions on which were paying minute attention to the relay, boiled over with anger at what users perceived as the French government's and media's complicity in this indignity. As one poster wrote, 'some Parisian editors, reporters and members of parliament ... put themselves on the side of criminals' (Ai de zhongdian 2008). To make matters worse, the Paris City Council granted the Dalai Lama honorary citizenship on April 21.

Historical grievances against the French-from the occupation of Tonkin in 1860 to a Chinese couple being strip-searched by French police after being falsely accused of

PORTAL Journal of Multidisciplinary International Studies, vol. 6, no. 2, July 2009.

Post-Mao, Post-Bourdieu: Class and Taste in Contemporary China, Special Issue, guest edited by Yi Zheng and Stephanie Hemelryk Donald. 
presenting a counterfeit note to the Paris luxury goods store Galeries Lafayette in February 2008-were quickly recalled in this context. On 10 April, a call was issued on Tianya - the largest Chinese-language Internet bulletin board (BBS), with over 80 million registered users - to boycott the French brands that have recently begun to loom large in the lifestyle of the new Chinese consumer class: Louis Vuitton bags, Peugeot and Citroen cars, as well as Carrefour, a supermarket-cum-consumer goods chain, which has over one hundred outlets in China. Carrefour was an obvious target because of its visibility and accessibility; in addition, shareholders of its parent company, Louis Vuitton Moët Hennessy (LVMH), were accused of financially supporting the Dalai Lama. The company issued several statements that neither it "nor individual shareholders support any organization or behaviour opposed to the interests of the Chinese government and people' (Qin Xuan 2008) and that, moreover, 'calls for a boycott of the Olympics [had] ulterior motives, and Carrefour would make its utmost efforts to support the Olympics' (Zhao 2008: 55). Yet the call to boycott Carrefour spread to more bulletin boards, blogs, and cellphone text messages. 'Boycott Carrefour circles' mushroomed on QQ, an instant message system that has 300 million registered users. On 10 April, 'Kitty Shelley,' a 27-year-old poster on Tsinghua University's Shuimu BBS, was reportedly the first to suggest that the boycott needed to be reinforced by demonstrations: 'students abroad are basically experiencing a "war" everyday, and we are just sitting here. Can't we do something?' (Zhongguo Xinwen Zhoukan 2008). In a later interview for a cover story in Zhongguo Xinwen Zhoukan ('China Newsweek,' no connection to the original Newsweek), 'Kitty Shelley' said that she had been raised in a Francophile family, and was particularly upset because she felt 'cheated' by France. Her post was rejected three times by the moderator before being allowed, and she felt worried she was 'going too far.' Yet on 15 April, the Foreign Ministry's spokeswoman, Jiang $\mathrm{Yu}$, called the calls for a boycott reasonable and lawful, and suggested that 'the French side should do some deep and hard thinking about it' (Xinhuanet 2008). This was the first time the government explicitly, though indirectly, endorsed a consumer boycott, and it was after this that the boycott became broadly visible to ordinary Chinese citizens.

France's president apologized to Jin Jing on television, and on 21 April his letter of apology was delivered to her in person by the chairman of the French National Assembly, but this was too late. On the two preceding days, thousands of placard- 
holding protesters had turned out in front of Carrefour stores in a number of cities, including Qingdao, Changsha, Hefei, Wuhan, and Kunming. In Hefei-where picketers briefly occupied the checkout counters and blocked the entrance to the store by holding up a long banner that read 'Tibet Will Forever Be an Inseparable Part of China' (Zhang \& Chen 2008) - and Wuhan, the stores were briefly forced to close. In Kunming, where the picket was organized by four young people in their early twenties but was soon joined by secondary and even primary school students, a few people turned out with placards to oppose the calls for the boycott, arguing that it was hurting Chinese employees and discouraging foreign investment. The picketers denounced them as 'traitors'; someone threw a bottle at them, and an old man threatened to post their photos on the Internet (Tang \& Chen 2008). Shoppers coming out of Carrefour stores were heckled as well. After a few days, the boycott appeared to be having some effect, as newspapers reported that Carrefour began returning unsold stock to suppliers (who were contractually obliged to take it back). It made little difference that shop assistants at Carrefour decked themselves out in 'support-the-Olympics caps' and pinned Chinese flags on their chests (Sina.com.cn 2008). In fact, when Jin Jing said in an interview that those who call for a boycott should be careful because it would hurt Chinese employees, sections of Internet opinion immediately turned against her-she was denounced as a traitor paid off by the French and an 'uncultured brainless cunt': 'She better disappear immediately, or she will die with her body in more than one piece'; 'The interest of a number of Chinese employees cannot be as important as the interests of a nation'; 'Even if we starve to death, we must ruin Carrefour. ${ }^{, 1}$ In the end, both 'Kitty Shelley' and the four organizers of the Kunming picket began feeling uneasy about the crowds, which now included seven-year-olds singing the national anthem, highschool girls collecting donations 'for the boycott,' and protesters with corporate T-shirts. But by this time, Kitty Shelley herself was being called a traitor by some on the Internet.

From blogs and bulletin boards, the boycott movement spread to the main portals. The Ministry of Commerce clearly began worrying about the fallout of the boycott among foreign investors, and started urging citizens to express their patriotism 'rationally,' reminding them that Carrefour had nearly 40,000 Chinese employees and sold almost exclusively Chinese goods. The newspapers picked up the cue (see Zhao 2008: 54), but,

\footnotetext{
${ }^{1}$ Comments from the www.163.com (Netease) forum, translated by Roland Soong (EastSouthWestNorth 2008).
} 
despite the blocking of access to some sites with posts calling for the boycott and featuring videos of pickets, the Internet resisted. Sina.com.cn, one of the largest Chinese portals, organized a debate with the title 'Patriotism: rational or passionate?' (Aiguo: lixing haishi xuexing ${ }^{2}$ ), with Lin Chengpeng representing the latter, and well-known Peking University sociologist Zheng Yefu the former viewpoint. ${ }^{3}$ The debate, conducted before a screen with a giant red heart, was introduced by a video that showed footage of protests outside and inside China, accompanied by this voiceover: 'In the face of the Dalai clique's conspiracy to split the Fatherland, in the face of Tibetan separatists' efforts to ruin the Olympics, the Chinese people's patriotic fervour erupted like a tsunami.' Readers were invited to vote on which of the two views they agreed with: 'Some patriotic actions may be extreme, but they are manifestations of national rectitude (minzu xuexing); as members of the Chinese race, we can only support them, not ignore them' (Lin's view); or 'Patriotism cannot be "hurt a thousand people, lose eight hundred of your own"; excessive patriotism may be laudable as an emotion (qing ke jia) but is not rational enough' (Zheng's view). Although, or perhaps because, Zheng's phrasing was more confused and self-contradictory than adversarial—indeed, it was so poorly phrased for a prominent scholar as to suggest he was afraid of challenging what seemed the popular view-he received only 13 percent of 4,334 votes, while 60 percent supported Li Chengpeng. On the other hand, the votes split about evenly (37 percent vs 36 percent) between those who agreed that the best way of expressing patriotism was to boycott foreign goods and those who said the best way to do so was to 'do one's own job well,' with only 11 percent choosing the answer that 'demonstrations by our overseas sons' were the best way. ${ }^{4}$ In another poll, on the People's Daily Online's Strong Country Forum (Qiangguo Luntan), 75 percent of some 2,500 respondents supported the boycott. ${ }^{5}$

Yet the boycott also had its vocal opponents. Bai Yansong and He Yanguang, two senior journalists respectively from China Central Television and China Youth Daily, posted opinions opposing the boycott on their blogs, attracting attacks and threats but also support. Bai, the better known of the two, did not dispute the reasons for the

\footnotetext{
2 I translate the term xuexing in this opposition as 'passionate,' but usually it means 'upright.' Because it includes the character 'blood,' it also conjures up images of a blood or kin relationship.

${ }^{3}$ Note, the transliterated formal name of Peking University has not changed, although it is in Beijing and is locally called Beijing daxue (Beida).

${ }^{4} \mathrm{http}: / /$ survey.news.sina.com.cn/voteresult.php?pid=23815 (accessed 29 April 2008).

${ }^{5} \mathrm{http}$ ://bbs.people.com.cn/voteResult.do?voteId=128 (accessed 24 April 2008).
} 
boycott: he admitted that 'during the Olympic torch relay ... what many Westerners did was ugly and dreadful,' and that if a city's mayor hung a human-rights banner from his city hall his protestations about having done his best were obviously disingenuous. But he suggested that 'if you don't get angry ... those troublemakers will just be remembered by people as a bunch of clowns.' He also argued that the boycott hurt Chinese employees and suppliers. He Yanguang used stronger words, comparing the boycott to an 'infectious disease' and commenting that 'some of the current opinions contain a Cultural Revolution flavour' (Tan \& Youtian 2008). For He, the best way to correct Western media's image of China was to allow more freedom of information (Mo Zhixu 2008). Han Han, a young writer who runs a popular blog, mocked the hysterical language of Internet nationalists (the so-called fenqing, or irate youth) and rejected it as a 'coercive, hooligan view of patriotism' (Han Han 2008).

Some French companies tried to pre-empt being impacted by the boycott by demonstrating loyalty to China's policies in Tibet. For instance, cosmetics maker Avène donated 200,000 yuan worth of sun protection products to People's Liberation Army and People's Armed Police officers serving in Tibet (Modern Weekly 2008). Meanwhile, the Carrefour boycott was petering out by the end of April, and on 1 May, police began dispersing pickets and arrested eleven people outside Carrefour stores in Beijing and Shenzhen. Largely supportive comments on a video of the arrests posted on the Internet suggest that at least part of the popular opinion followed the official change of tone (comments supportive of the boycott were now being deleted). ${ }^{6}$

The Carrefour boycott achieved the largest scale, by far the highest visibility, and perhaps the most success of any such initiative in China in recent years, but it was typical of a growing number of boycott appeals. ${ }^{7}$ It targeted products associated with middle-class consumption. (It was noteworthy that, in response to the boycott, Carrefour reduced the price of rice and oil, clearly trying to compensate by attracting low-income consumers who normally do not shop at Carrefour and who had been hit by rising food

\footnotetext{
${ }^{6}$ See the video recording on $\mathrm{http}: / / \mathrm{msn}$.vodone.com/msn/vodplayer/content/142673.shtml (accessed 3 May 2008).

${ }^{7}$ Simultaneously to Carrefour, Coca-Cola was attacked by Chinese bloggers and forum users for a poster that displayed joyfully shouting Tibetan monks and the words 'MAKE IT REAL.' Coca-Cola got off the hook by issuing a statement expressing 'regret' that the poster, apparently photographed in 2003 at the Bremen railway station in Germany, had been 'misunderstood' (EastSouthWestNorth 2008). After the Carrefour affair, calls for a boycott of French goods flared up again with the auction of the Yves Saint Laurent-Pierre Bergé collection in Paris in February 2009, which included two figures looted by French troops from the Summer Palace in Beijing in 1860. These calls, however, had far less resonance.
} 
prices.) It employed a strident rhetoric of nationalism in which the actual offence quickly became obscured and almost irrelevant beneath a much wider discourse of perceived grievances, in which foreign powers are intent on preventing China from becoming strong. The rhetoric has a striking unity, and any internal dissent is attacked as traitorous. And the protagonists of the boycott, both promoters and opponents, were young people intimately involved in-some even created by - the commodity economy.

Commentators in China often describe nationalist fenqing as typically less educated, less financially prosperous, more uneasy with globalization and more concerned about social injustice than the 'elite' (jingying), who disdain the irrationality of the former and are in turn accused by them of being in love with Western liberalism. ${ }^{8}$ It is true that some threads on 'elite' portals, discussion forums and blog sites - such as Wenxuecheng, KDnet, or My1510 — displayed a much greater diversity of opinions (Sitai 2008). But the jingying/fenqing division-which would mirror the usual description of Chinese intellectuals as divided into 'nationalist,' 'liberal' and 'new Left' camps - seems far less absolute than the pundits who describe the two camps as two distinct subcultures locked into a bitter rivalry would have it. Neither Kitty Shelley with her Francophile family nor her fellow activists with their English nicknames, cutesy Web addresses and avatars - described as typically under-30 computer engineers and white-collar corporate employees - fit the image of the blustering, foulmouthed fenqing who 'inhabit' some of the more extreme forums like Tiexue ('Iron Blood'). Rui Chenggang, the sleek media hero of an earlier boycott campaign, is even farther away from that stereotype.

\section{The Starbucks affair}

A year before the Carrefour boycott, the Chinese Internet resounded with a campaign to oust Starbucks from its shop inside the Forbidden City in Beijing, a World Heritage site whose integrity is supposedly protected according to strict UNESCO guidelines. The outlet's opening seven years earlier had met with online criticism, but no movement had grown out of it (People's Daily Online 2000). This time, the campaign was triggered by a Yale-educated television host called Rui Chenggang, who on 15 January 2007 called for the removal of the shop, saying that it 'trampled over over Chinese culture.' In the following three days, dozens of newspapers carried prominent stories about the

\footnotetext{
${ }^{8}$ For a typical analysis, see Tang Rong (2008).
} 
controversy and, supposedly, half a million people signed Rui's online petition.

Although the incriminated shop hurriedly took off its conspicuous sign, an online poll on the Sina.com.cn website still found that 84 percent of over 10,000 respondents agreed that Starbucks should move out. ${ }^{9}$ In July, it did so.

Soon, Rui selected his next target: American Express sponsorship signs. As he said in an interview with The Guardian newspaper:

'I really loathe them. The introduction to every site says, "Made possible by American Express." It is as if the Mona Lisa had a label saying, "Made possible by the People's Bank of China," Mr Rui said. 'But please don't interpret this as an act of nationalism. It is just about we (sic) Chinese people respecting ourselves. I actually like drinking Starbucks coffee. I am just against having one in the Forbidden City.' (Watts 2007)

Rui knew how to present his campaign to Western media. He couched it in terms that were quite similar to the anti-globalisation consumer politics of North America and Western Europe: 'We need to embrace the world, but we also need to preserve our cultural identity. There is a fine line between globalisation and contamination' (Watts 2007). ${ }^{10}$ Rui pointedly cited the example of Western Europe, where Starbucks encountered strong opposition even at far more innocuous locations than the imperial palace. Rui considered it a shame for China to be such a 'pushover' as to become Starbucks' second largest market in the world without mustering any similar opposition, and cited Westerners, 'especially intellectuals,' who also considered Starbucks in the Forbidden City 'disrespectful' (Rui 2007d). By educating his readers that, 'though in China's large cities, Starbucks is a lifestyle choice of white-collar yuppies (xiaozi), in America and other countries, it is just the coffee equivalent of McDonalds' (2007d), Rui was explicitly attempting to awaken the missing antiglobalist 'slow food' consumer consciousness in the Chinese middle classes, and appealed to 'taste' as well as national sentiment. Rui's approach was to engage rather than to attack. He had first mentioned his objections to Starbucks' CEO, Jim Donald, at a 'Yale CEO party'-he wrote that 'the other CEOs' present had all agreed with him — and followed up with a friendly email, to which he received a polite reply (Rui 2007c). He also asked an 'American opinion leader' to pass on his message to another top manager of Starbucks and expressed his confidence that the company would 'make the right decision.' Moreover, although in his original post he asked the Chinese companies Lenovo and Haier to

\footnotetext{
${ }^{9} \mathrm{http}: / /$ news.sina.com.cn/z/starbucksdiscuss/index.shtml, accessed 20 January 2007.

${ }^{10} \mathrm{I}$ thank Lorri Hagman for pointing out this article to me.
} 
replace American Express as sponsor for signs in the Forbidden City_ 'if there really is that little funding for the protection of cultural heritage' (Rui 2007b) — he later changed his mind and declared that sponsorship signs of Chinese brands are as unacceptable in the Forbidden City as Western ones (Rui 2007d).

All in all, Rui was casting himself as the friendly, cosmopolitan, yet firmly patriotic modern Chinese citizen for whom the hedonistic lifestyle of a showman does not preclude a commitment to 'strengthening the nation.' As he said: 'In retrospect, the more I travel around the world, the more of an internationalized Chinese I am, the more I know how to cherish and respect my own national culture.... Working, studying and living in many countries around the world, I often made an earnest effort to rectify the reputation of the Chinese people' (Rui 2007d). Indeed, another blogger expressed his admiration for Rui's tolerance and restraint in avoiding the use of the inflammatory language that is ubiquitous in nationalist Web posts, attributing this to Rui's qualities of a 'global scholar' (Mu Rong Zhu Ning 2007).

Still, Rui's elitist posture of the stern but just schoolteacher was closer to that familiar from Chinese media than that of the global anti-globalist Left. In another blog entry from the same period, entitled 'Don't let Western trash feel too good in China,' Rui railed against a Westerner who did not obey the rules at a ski resort near Beijing (he refused to keep to the beginners' slope and was rude to the attendants) and called on his compatriots to be friendly towards foreigners who are friendly, but 'for those foreigners who do not respect Chinese people, there should absolutely be ... no kid gloves.' $\mathrm{He}$ warned that while there were 'many, many foreigners in China who are outstanding, who respect and love China,' there was also 'a fair share of trash and losers' (Rui 2007a).

For those used to the strident tone that nationalists debates on the Chinese Web tend to take, the response that followed from his online readers came as no surprise. ${ }^{11}$ When

\footnotetext{
${ }^{11}$ Despite heavy moderator presence — which is mandated to filter out 'harmful' content—flaming seems to be accepted on most Chinese blogs and bulletin boards, and often extends to death threats. Online violence, sometimes leading to offline attacks, has been documented in a number of instances, often but not always linked to nationalistic causes. For example, in 2006, when China offered aid to tsunami-struck Indonesia, a number of posters on Internet forums who opposed the move because of Indonesia's treatment of its ethnic Chinese minority, issued calls to 'kill Indo pigs' or 'send troops to Indonesia.' One participant in the discussion on Tianya wrote: 'I want to be a suicide bomber and go to the Indonesian embassy.' In another infamous case the same year, a man denounced a college student he suspected of having an affair with his wife on Tianya. In response, readers teamed up to uncover and then post the
} 
one of them issued a call to bomb Starbucks, Rui felt prompted to post a clarification on his blog: 'I've never called for the bombing or attacking of Starbucks or any other company or individual ' (Rui 2007d). In a posting whose title, 'Harmony is the way,' echoed the Party's current favourite slogan ('harmonious society'), Rui reported having made an effort to explain his opinions to 'Westerners' and 'let them understand the broadmindedness [or magnanimity, kuanhou de xionghuai] of the Chinese people' (Rui 2007e).

\section{'Why don't they make some foreigners kneel?': Consumer boycotts in Chinese media}

The Carrefour and Starbucks affairs are only two of the latest in a series of boycott calls - invariably originating on the Internet, and then usually picked up by mainstream media - against foreign companies, products, and sometimes Chinese entertainers accused of offending China's national dignity. Most of these calls ended with an apology by the putative offender.

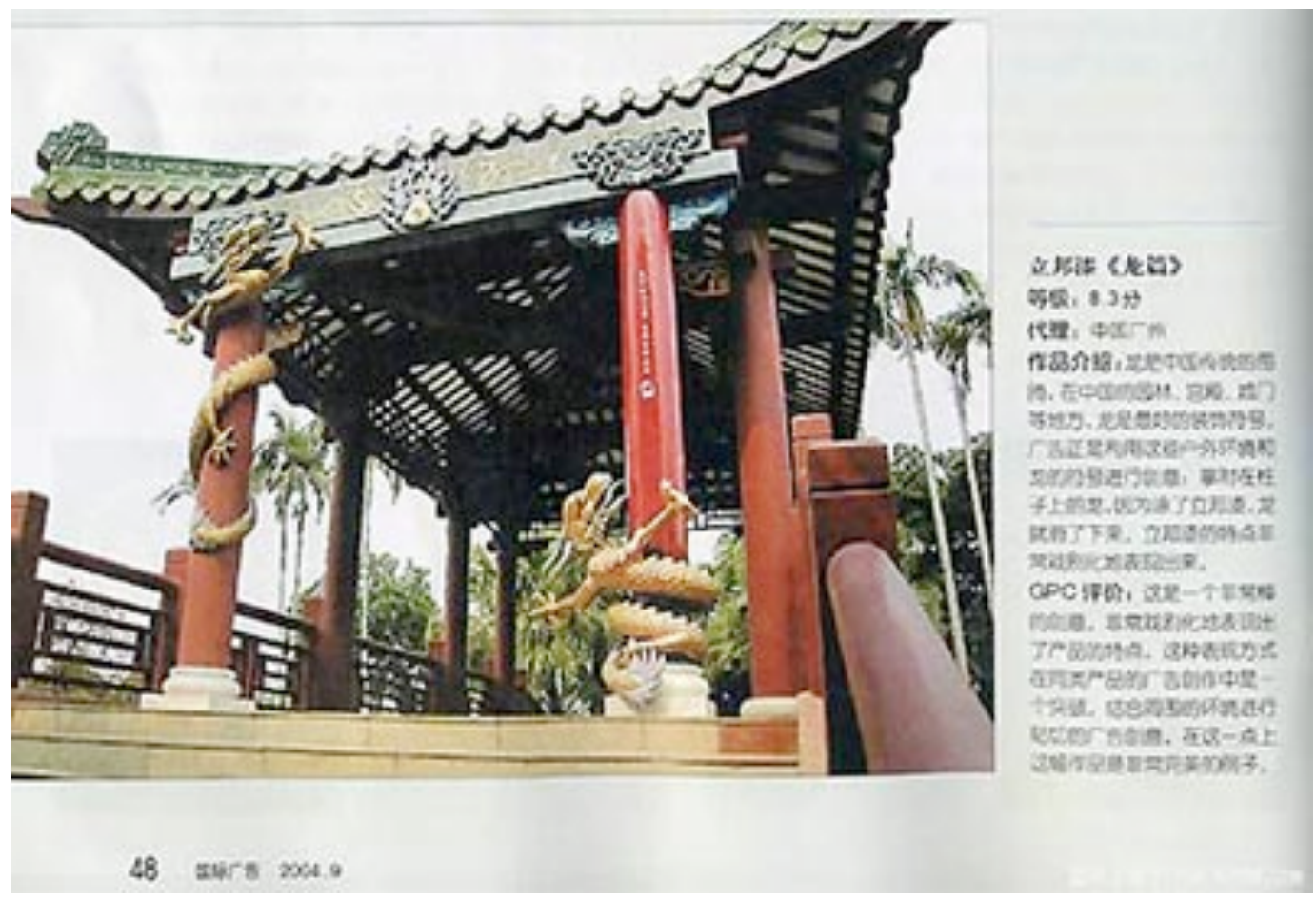

Figure 1: Nippon Paint advertisement in Guoji Guanggao. Reproduced in Yang (2004).

student's address and telephone number, then showed up at his university and his parents' home, forcing him to drop out of school. Others denounced the university for not expelling him, with one poster saying it should be 'bombed by Iranian missiles.' Many others said the student should be beheaded, beaten, or have his hands chopped off, or that he and his alleged lover should be drowned. See French (2006). 
September 2004 saw a wave of protests against an ad for Nippon Paint, a marketleading Japanese-owned company, which had been reproduced in Guoji Guanggao (International Advertising), an advertising trade magazine. The ad, produced by the Canton branch of Leo Burnett, depicted a traditional Chinese pavilion, with carved dragons coiled up around its front pillars. But one of the dragons was pictured slumped at the bottom of the pillar, which was painted a shinier red than the others. The message was that Nippon's lacquer, used to coat that pillar, was so smooth that the dragon could not help sliding down it. The magazine praised the originality and forcefulness of the ad as a 'breakthrough' of creativity, but Internet posters described it as 'evil' (Yang 2004). People's Daily Online, the website of the Chinese Communist Party's flagship newspaper, invited readers to express their views on its article, entitled 'How Can We Recognise International Advertising That Harms National Dignity?' The article raised the question whether Guoji Guanggao's defense - that by reproducing the ad it was not supportive of it but wished merely to educate readers and incite discussion about negative trends in advertising - should be accepted as a genuine apology or seen as an effort to raise sales through deliberate provocation. All responses selected for posting by the website's managers were unequivocally condemning of the ad, with the most outspoken calling not only for a boycott of Nippon Paint but also-referring to the publishers of the magazine - for 'hurting this scum' (People's Daily Online 2004a). On another website, a poster explained why he considered the ad so offensive: 'The symbol of our Chinese race - the sacred and mighty, inviolable dragon! The Chinese dragon here plays the role of a clown, the inglorious role of being humiliated! ... Who was it that directed Nippon Paint to make such an ad!' The poster went on to 'sternly demand an apology to the Chinese people' (Kafei 2004).

In December, Nike apologized for a television commercial featuring NBA player LeBron James that had to be taken off air after a ban imposed by the State Council. The ban said that the commercial had violated Articles 6 and 7 of the Guidelines for the Management of Television Advertising, which say that 'television advertising should protect the dignity and interests of the state and respect the traditional culture of the Fatherland' and 'may not defame national customs and lore.' According to an article on the People's Daily website, this was a response to complaints by viewers who accused the ad of showing 'American culture defeat Chinese culture' or even of defaming China (People's Daily Online 2004b). The commercial showed LeBron James fight and defeat 
two Chinese-looking figures - an old wizard and a female fighter-and two dragons. The article included a sampling of netizens' opinions, some of which condemned the advertising, while others charged these with excessive sensitivity. The tone of the article was set by an 'expert', a professor of advertising at China Media University, who figured that the offensive advertising was not the result of malicious intent but of cultural ignorance, and called for more regulations to curtail what he called 'blind and excessive creativity.' The article recalled that a previous pair of Toyota print advertisements encountered similar protests and resulted in an apology by the company. In one of the ads, two Chinese stone lions salute the Prado four-wheel drive as it passes by (selling line: 'Prado_-You Can't Help Respecting It'), while in the other, a Land Cruiser tows a stalled Chinese-made Dongfeng military lorry in a mountain wilderness. (Coincidentally or not, the brand name Prado has been translated as Badao, meaning 'hegemony' or 'dictatorship' in Chinese.)

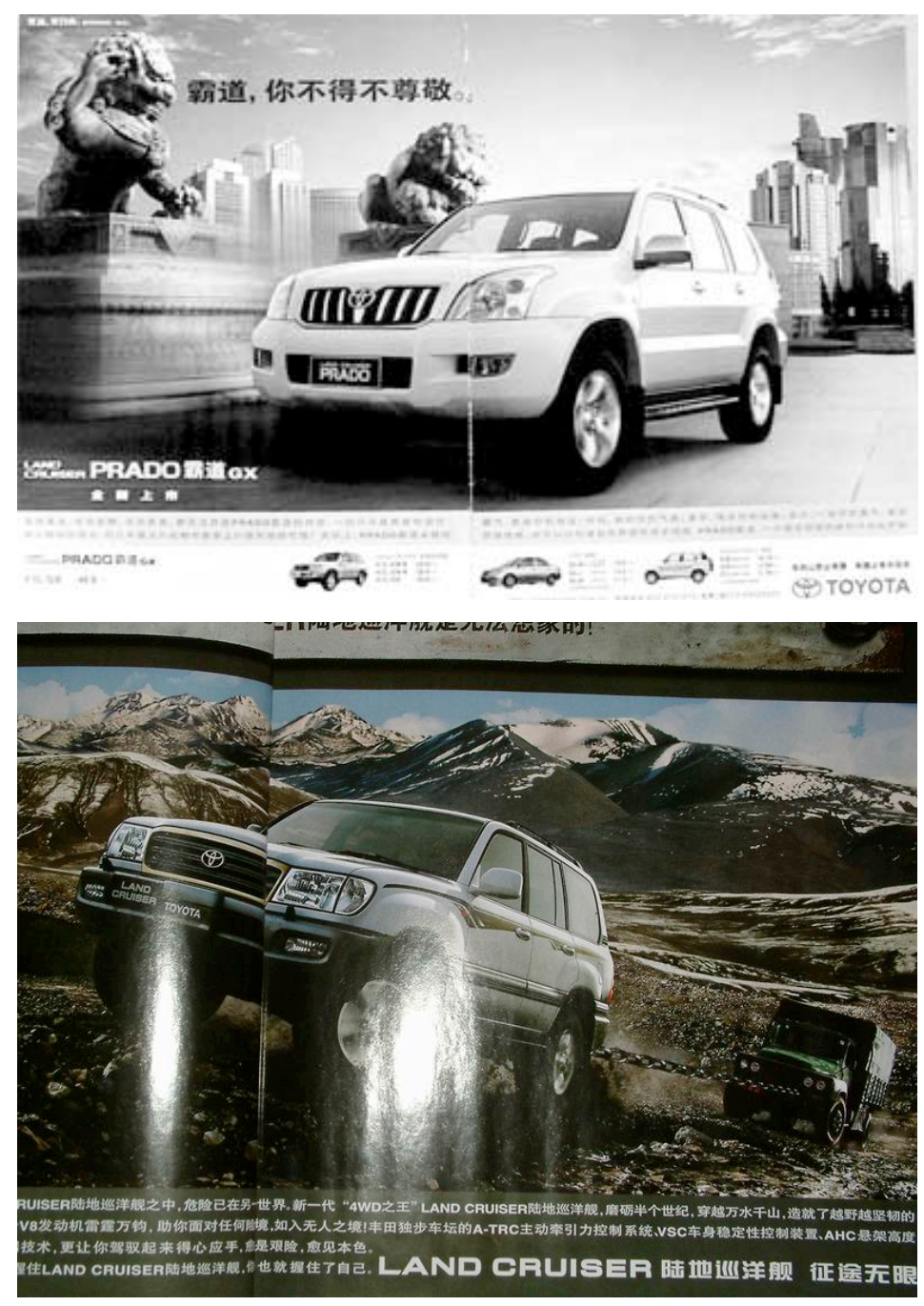

Figures 2 and 3: Advertisements for Toyota Prado and Land Cruiser. Reproduced in Xinhua 2004. 
The Xinhua News Agency reported that the ads were 'seen as degrading to the national motor industry and injurious to the national sentiments of the broad masses of viewers' (Xinhua 2004). Toyota, the advertising company and the magazine that published the ads all apologized. In its response to readers, the magazine, Guoji Guanggao, stated: 'because our political level is not high, we were unable to identify the pictures that could easily provoke associations that hurt national feelings ... We recognize the gravity of the issue' (Xinhua 2004). Even so, a number of counter-ads fabricated by protesters continued to circulate on the Internet. In one (figure 4), with the caption 'Prado-You Must Seize It,' the two stone lions were crushing the car with their paws; another showed the lorry in tow shouting abuse at the Land Cruiser; in the third, a donkey was towing the Toyota. The mildest had the Land Cruiser on the lorry's platform, with the caption 'Dongfeng Auto Company's Honorary Product: Dongfeng, Designated Instruction Vehicle for Toyota Land Cruiser (figure 5).

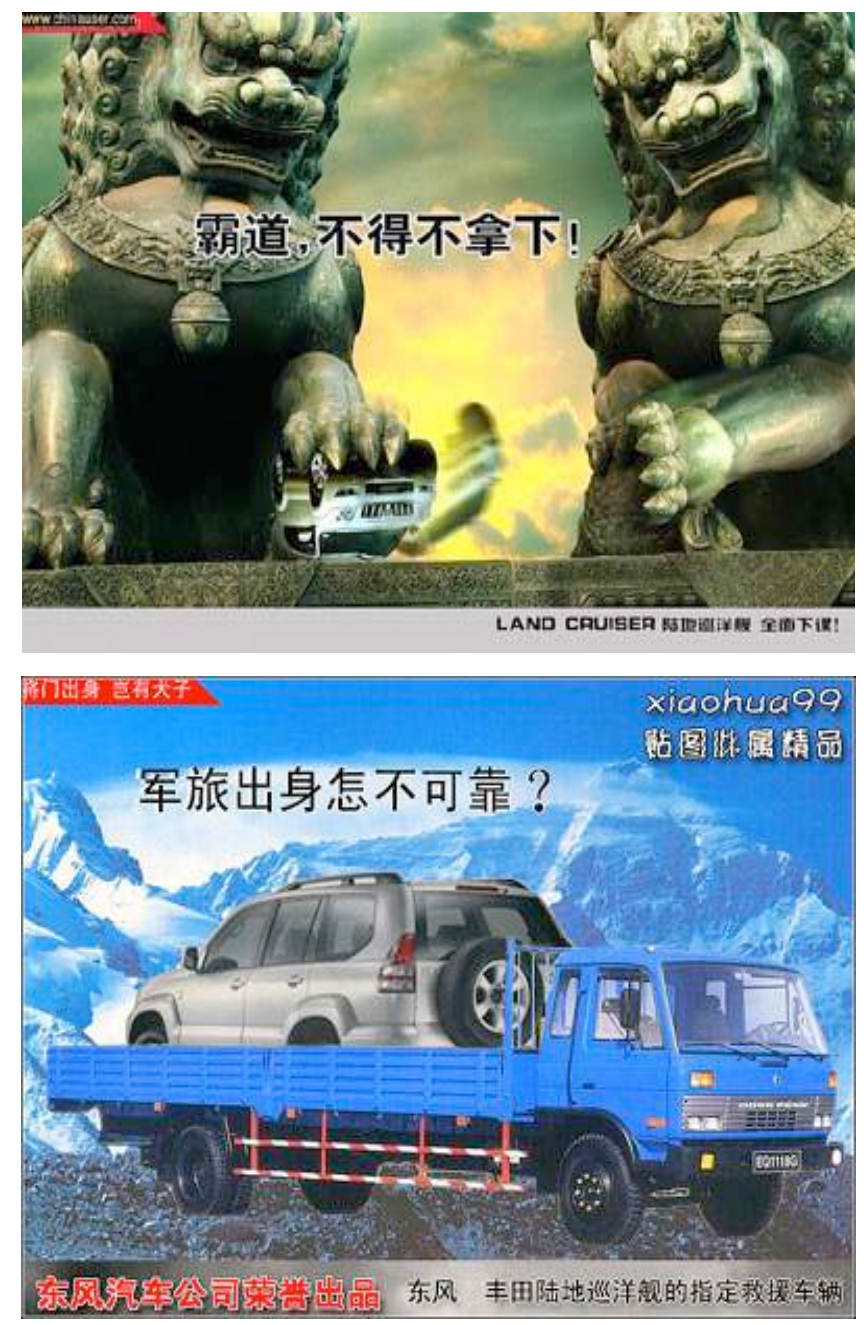

Figures 4 and 5: Online spoofs on the Toyota advertisements. http://life.news.tom.com/1013/2004923-5583 to 5586.html (accessed 9 June 2006). 
The trend continued in 2005, when McDonalds aired a television commercial—also by Leo Burnett - in which a customer begged a restaurant manager on his knees to honour his expired discount coupon. Reportedly, this scene was included in the nationally broadcast ad although the China Advertising Association, which had vetted the copy at Leo Burnett's request, recommended cutting it out. This ad too gave rise to caricatures, in one of which the clown that McDonalds uses as a mascot in China pushes a customer down on his knees in front of the 'golden arches.' 12 The press reported of irate viewers, such as the one in Zhengzhou who called a local television station asking, 'Why don't they make some foreigners kneel?' in the ad (People's Daily Online 2005). Provincial industry and trade bureaus across the country then launched investigations, accusing the ad to have violated Article 7 of the Advertising Law, which states that advertising must not 'harm the public interest of society' or 'impede the public order of society and violate good social customs' (Huashangbao 2005). In addition, the Zhejiang Industry and Trade Bureau said the ad violated consumer protection law, 'violated human dignity, offended public morality, and contained fabrication' (Wang Guanghui 2005).

Around the same time, Internet users launched a separate petition campaign calling for the boycott of 22 year-old Taiwan media personality Yang Chenglin, who enjoyed a large (particularly teenage) fan base in the mainland, for her appearance in a Taiwanese TV programme several years earlier. The sequence they posted showed her first responding incorrectly to the question how long the Anti-Japanese War lasted, and when told that it lasted eight, not eleven years, answering: 'Oh, just eight years!' The posters, who found this offensive, compounded their charge of antipatriotism with an unrelated quote from Yang: 'In my previous life, I must have been Japanese! Walking in the snow wearing a kimono, that feels really noble!' After the campaign, Yang reportedly did not appear in the mainland for a year, and when she did she made a tearful apology to a journalist. The scene, as reported in Huaxi Dushi Bao, is eerily reminiscent of the enactments of contrition by victims of Cultural Revolution struggle sessions. Yang expresses her gratitude to those who called for the boycott for 'making me see my errors' and asks her fans to 'give me a chance to correct my mistakes.' She promises to 'make an effort to work [on myself], to bring to everyone a Yang Chenglin that is completely different from before.' In this story of thought crime and reeducation, the 'Net hunters' who successfully censor Yang are referred to as wangyou (Net friends),

${ }^{12}$ http://business.sohu.com/s2005/maidlad.shtml (accessed 29 August 2009). 
obviously a positive term, while Yang speaks in the language of a reformed criminal.

Not everyone was persuaded. In January 2007, another net campaign linked two favourite targets: this time, an ad featuring Yang Chenglin resulted in calls for the boycott of McDonalds, which hastily pulled the ad off air (Sina.com.cn 2007). Posters responded with the usual enthusiasm: on Tianya, for example, a post by mandymeng1984 received hundreds of responses in one day. The tenor of the replies was in the familiar bloodcurdling vein: youke7699 wrote, for example, that 'McDonalds is a stupid cunt (shabi), and it asked another stupid cunt to speak for the hamburgers. Fuck them! No Chinese with any blood in his veins should eat those' (Tianya 2007).

Though McDonalds stopped airing both ads, the dust around them did not settle. As late as 16 March 2006, an anonymous poster on the BBS of a hospitality industry website, HC360.com, suggested 'kicking McDonalds out." ${ }^{13}$ The tenor of the posts in the thread was unanimously condemnatory. In an online survey, 87 percent of over 6 thousand respondents agreed with the statement that they were 'extremely outraged' (ji wei fennu) by the ad. ${ }^{14}$ The same moral outrage enveloped print media, television and radio, each hastening to add its criticism. As one journalist commented, it was 'as if whoever has fallen behind is unpatriotic' (Li Yanjun 2006). The effect, again, was a bit like a struggle session: if you were not wholehearted in your criticism, you could be the next to be struggled against.

\section{From nationalism to the politics of taste?}

Consumer boycotts in China appear to fit more into the pattern described by Karl Gerth in his work on the politics of 'national products' (guohuo) in Republican China than into the kind of fair-trade, ethical, ecological, local-food, slow-food, or antiglobalization politics that characterize Western consumer movements. ${ }^{15}$ Gerth argues that the 'national products' movement - manifested in the first place in boycotts of Japanese goods - projected onto commodities aspirations of national unity and of living 'modern' commodity-filled lifestyles without surrendering to foreign imperialism. The movement and its 'nationalistic spectacles,' he writes, 'began to create an environment in which patriotic (or anti-patriotic) practice became inescapable' (Gerth 2003: 207).

\footnotetext{
${ }^{13} \mathrm{http}: / /$ comment.info.hc360.com/comment.asp?, accessed 16 May 2006.

${ }^{14} \mathrm{http}: / /$ vote.info.hc360.com/dcmanage/dc-jg1.asp?su_id=3801, accessed 9 October 2006.

${ }^{15}$ On consumer nationalism, see Wang (2006) and Dong and Tian (2009). On nationalist marketing, see Li (2008).
} 
Thanks to today's (multi)media, the possibilities and reach of nationalistic spectacles have expanded to such a degree that actually giving up the consumption of foreign goods has become unnecessary: to exhibit patriotic behaviour or unmask unpatriotic behaviour, it is enough to engage in the symbolic ostracism of particular brands or individuals. Indeed, one needs do no more than hit the character 'ding' under a post denouncing Carrefour or McDonalds.

In this way, of course, Chinese consumers are no different from their Western counterparts who symbolically demonstrate their opposition to globalization, or simply to the USA, by publicly refusing to eat at McDonalds or drink coffee at Starbucks, while nonetheless consuming other products of 'American' multinationals. ${ }^{16}$ Translating this observation into the language of the grand debate on civil society in China, then, one can conclude that the Internet gives rise to the same type of consumer activism in China as it does in the West. But, as we have seen, while the technique of mobilization may be similar, its ideology is quite different. The link between prestigious lifestyles and the criticism of globalization - in any case restricted to a small group of intellectuals in China - or demands for the decent treatment of workers or animals, in other words, the link between ethics and taste that is crucial to the politics of consumption in the West, is yet to be made in China. Concern with healthy nutrition has an unbroken tradition in China, but precisely for that reason it is harder to link it to 'modern' lifestyle trends. While the sales of 'green foods' are growing, most consumers are likely to choose them as a way of avoiding potentially unsafe local products, rather than as a way of supporting them: the concept 'buy local' has yet to be introduced to China. In the context of a crisis of confidence in food safety, McDonalds may in fact be seen as a more reliable alternative.

Against this background, Rui Chenggang's attempt to introduce elements of antiglobalization discourse into the context of a consumer boycott and educate his audience in matters of taste is interesting, even if the central element of his initiative, and the one that found most resonance with the public, was conventional nationalism. Indeed, conventional media — which had, in the past, either ignored such campaigns or taken the

\footnotetext{
${ }^{16}$ As the Carrefour case shows, consumer boycotts are manipulated by the Chinese state far more directly than they are by Western states, and official condoning or censure can have a major impact on the dynamics of a boycott. Yet, like many other manifestations of Chinese nationalism, the boycotts are not orchestrated by the state but are genuinely 'civil' initiatives (see Nyíri \& Zhang 2010). For another discussion of 'state influence and consumer autonomy,' see Dong and Tian (2009).
} 
nationalist side - reacted in a more complex fashion this time, almost certainly under guidance 'from above.' They reproduced readers' opinions both supporting and opposing Rui's initiative and, generally, described the conflict as one between conservation and commercialization, not China and the West. Guangming Ribao, traditionally considered the Party's ideological mouthpiece, ran an article advocating greater attention to protecting the authenticity of the environments in which cultural monuments are located, rather than just the monuments themselves, as is often the case with tourist sites in China whose surroundings are frequently razed to make room for a newly built souvenir street. (True to its credentials, Guangming Ribao illustrated this on the examples of the former residences of Mao Zedong and Zhou Enlai: 'though the surroundings have been beautified,' it observed, 'there is nothing left of the environment in which the arduous struggle of those days took place' [Guangming Ribao 2007a].)

Unusually, also, Guangming Ribao — which had remained aloof from the McDonalds and other affairs - opened a debate on the Starbucks issue. In it, a professor of art history called Rui's statements 'a bit extreme. Don't we Chinese sell Coke and other foreign drinks in our shops too? After all, every traditional Chinese cultural venue can't say no to foreign brands!' (Guangming Ribao 2007b). Nearly all articles asked why, if Starbucks is inappropriate for the Forbidden City, should various Chinese snack and souvenir vendors not also be asked to leave. (They have not been.) A commentator in Southern Metropolis pointed out the irony of Rui's using Westerners' opinions to underpin his crusade not to defer to Westerners and called the crusade an 'expression of a lack of cultural self-confidence.' He suggested that 'the fateful question of the coexistence of commercialization with traditional culture surely cannot be solved by simply choosing one and rejecting the other '(Zhou Qing'an 2007). The popular New Beijing News wrote:

When we extend the topic of preserving traditional culture too far beyond the topic, people tend to get lost in recollections and fear about the wounds of history, or else get mired in self-satisfaction about history. At that point, even if Starbucks moves out, 'Zhang-bucks' or 'Li-bucks' will move in. Influenced by such discussions, it is often hard, because of the emotions of the crowds, for officials in charge of cultural preservation to focus on the real goals of conservation.... If we simply see Starbucks moving into the Forbidden City as 'foreign peddlers usurping the dignity of the heavenly dynasty,' that is disrespecting both traditional Chinese culture and the rules of global business. Besides, we can hardly avoid discussing the fact that those who allowed Starbucks to move into the Forbidden City in the first place were, sadly, Chinese people themselves. (Xin Jing Bao 2007) 
As a matter of fact, 'Zhang-bucks' - in the form of the Forbidden City Café, which served Chinese tea as well as coffee, and operated under the authority of the Palace Museum-moved in as soon as Starbucks was out ('Forbidden City Café' 2007). Of course, it is possible to oppose multinational chains and support small-scale local businesses without nationalistic arguments, and that is precisely what Rui had attempted to do, especially in his English-language interviews. But the Chinese public failed to appreciate the distinction, and for much of a live online talk show on the Netease portal, Rui was forced on the defensive and called himself 'a patriot, not a nationalist' (Netease 2007). And when Starbucks found itself in hot water again later the same year, it was on environmentalist grounds. On 30 and 31 October, two articles in the Beijing Evening News accused the company of ignoring of the city's water-saving guidelines due to its practice of setting taps on coffee workbenches to flow constantly, and thus wasting over 100 tonnes of water in more than 50 Starbucks outlets in Beijing. The reports were soon picked up by mainland media and circulated on the internet, and the People.com.cn website conducted an online survey in which some 90 percent of 2,434 respondents considered Starbucks to be guilty of wasting water.

Before the unprecedented success of anti-Carrefour mobilization, there had been signs that boycotts based purely on nationalistic arguments were attracting less interest, and that discussions around them were shifting to questions of authenticity, wholesomeness, tradition, and class - in other words, matters of taste. Even as the Starbucks controversy was raging, on 7 March 2007 a poster on Tianya tried to launch a campaign against Kentucky Fried Chicken (KFC). Perhaps because KFC has been present in China longer than its competitors (since 1987), has spread even to relatively small cities (it has over a thousand outlets and, according to a 1999 survey by ACNielsen, was the 'most recognised global brand in China' [Adler 2003]), and its stores have a more low-key feel to them, customers may perceive it as being more 'local.' In any case, it has in the past escaped attacks. This time, its Spring Festival billboard advertisement aroused poster Lao Chu's ire. The billboard uses the format of a Chinese new-year print featuring a baby boy - the bringer of good fortune in such prints - carrying a familysize takeaway bucket of chicken. The boy is flanked by two Chinese lions that appear seduced by the Family Bucket (Quanjiatong), and the image is framed by a traditionalstyle couplet: 'Prosperity and fortune go into the Family Bucket; year after year will be happy and harmonious' (Fu dao yun dao Quanjiatong, sui sui nian nian le rong rong). 


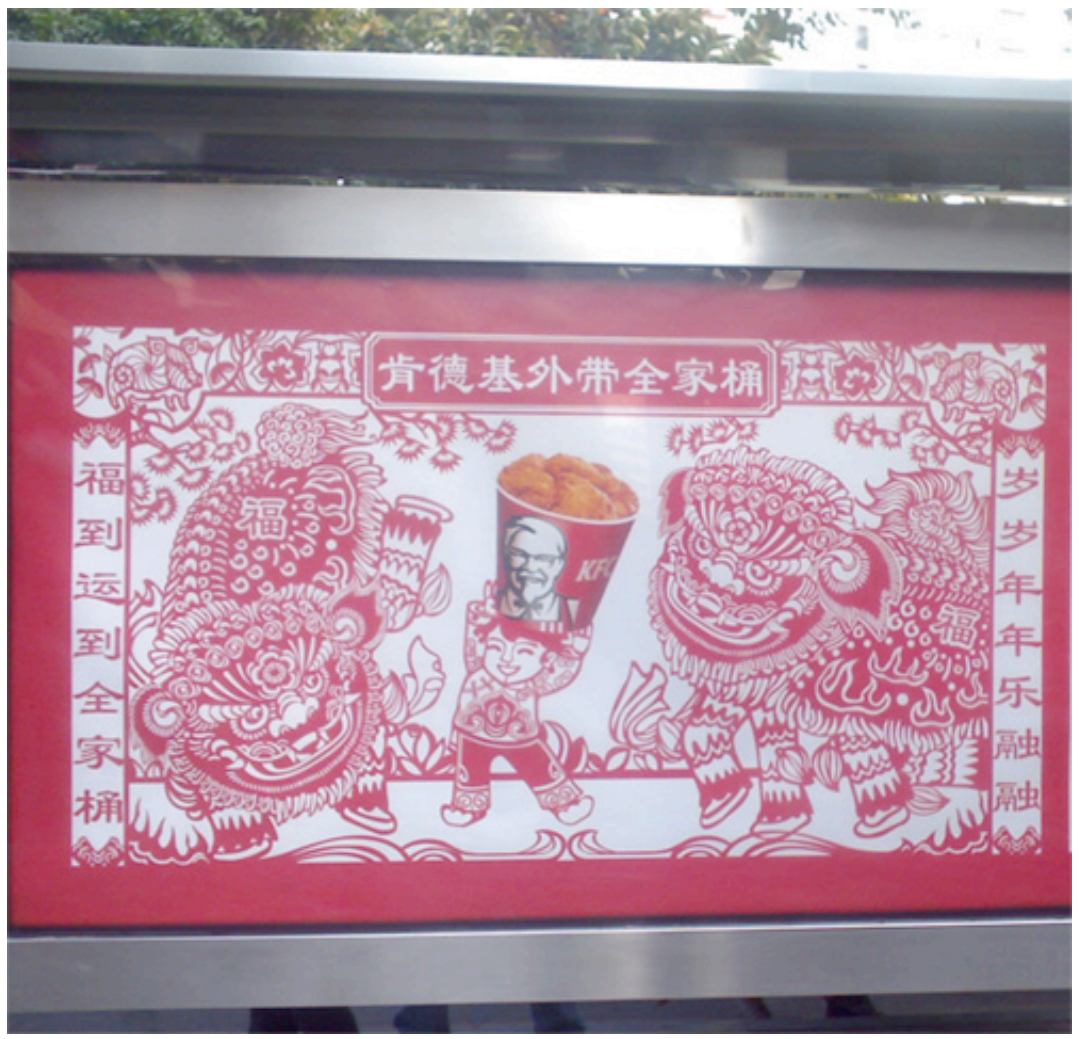

Figure 6: Kentucky Fried Chicken advertisement at a Beijing bus stop, 2007. Photo by author.

Lao Chu assailed the ad for 'profaning traditional Chinese culture' and, in well-tried language, accused KFC of plotting to 'subjugate not only the Chinese baby but also the Chinese lion' and of having 'gravely insulted the national dignity of all Chinese people' (Lao Chu 2007).

An increasing number of international brands have been trying to link themselves to such traditional gift-giving and feasting occasions as the Spring Festival and the MidAutumn festival. For example, Ferrero-Rocher's chocolates have become a common Mid-Autumn gift instead of the traditional mooncakes, perhaps because they are round and white like the moon. Nowadays, department stores and supermarkets offer a variety of eye-catching Mid-Autumn gift sets containing chocolate, French wine, or even Nescafé. As habits of celebrating holidays are rapidly changing-Spring Festival, traditionally the time for a family get-togethers in one's ancestral village, is now a popular occasion to travel abroad - the idea of eating takeaway Kentucky Fried Chicken instead of home-wrapped dumplings is, perhaps, no longer inconceivable.

Lao Chu's case against Western junk food invading China's most important festival seemed as strong as Rui Chenggang's, and the lions prancing around the KFC bucket 
appeared to guarantee another juicy scandal. Yet - whether because the idea of 'subjugating lions' with fried chicken was pushing the limits of absurdity or because netizens were simply getting tired of such calls to arms - the campaign fizzled out spectacularly. Lao Chu's post aroused only a handful of hardliners: 'Evil People's Tales' (Eren Chuanshuo) speculated that young people in China have been 'poisoned' by foreign junk food to the extent that they were now addicted, and Happyer-1 expressed outrage at another ad, in which, he wrote, KFC advertised a foundation designed to teach Chinese people about healthier food. Overall in the debate, however, comments in support of Lao Chu were far outnumbered by sceptical, sarcastic and dismissive ones. Several posters said they liked the billboard. A number of them praised international chains for 'knowing how to hook onto local culture' at a time when Chinese no longer care about it. 'Look at education these days! How many schools take Chinese language seriously_it's all English from dawn till dusk!' — commented 'Beast Without Tears' (Shou Wu Lei). 'KFC still remembers these elements of Chinese tradition, but Chinese people themselves may have forgotten them all. How many people in China can still make paper cuts? How many families still paste couplets on their doors and flowers on their windows?' —asked 'Merry Beggar' (Gai Xiaoyao). 'What's the use of scolding others? In trampling upon their own traditional culture, every Chinese is a perpetrator'-commented 'Thread-bound Lip Ointment' (Xianzhuang Chungao). A few others dismissed Lao Chu's post as 'rubbish,' sniggered at him for having nothing better to do, accused him of working for McDonalds, or simply said that they had never noticed the billboard.

The debate then drifted off in a dietetic direction: was Western junk food bad for you? Because of the traditional importance attributed to food in Chinese thinking about health, child nutrition has become a battleground contested by parents and grandparents with traditional beliefs, consumer goods companies targeting a generation of single and therefore supposedly spoiled children, and medical professionals with a Westerninspired view on health (see Jing 2000). In this particular debate, Happyer-1 angrily rejected KFC's latest efforts to recast itself as a nutrition expert, 'as if Chinese people had no idea about nutrition;' but other posters wrote that, on the contrary, Chinese people's lack of health education was responsible for KFC's popularity. One, Lishui Qingyun, laid the blame for that at the feet of the Chinese government, pointing out that 'abroad, KFC is banned from school cafeteria' and saying that instead of cracking down 
on it, the government should invest its energies into educating people about 'what kind of food is junk food.' Some readers rejected 'junk food' altogether, others wrote that was okay in moderation, but several also believed it was the responsibility of parents and teachers, not outsiders, to tell children when to stop. There were also a few who thought Chinese food was no healthier: 'Bounded Universe' (Zhongqian Shijie) pointed out that 'people say junk food is bad but eat food that's even more junk, like youtiao' (fried dough sticks). Hisqs added that 'it's Chinese food these days that is a hodgepodge of junk' and accused Chinese restaurants of reusing oil and the broth used to cook Sichuanese hotpots. Videoseven refused to call KFC 'junk' and wrote that it compared favourably to the standards of hygiene and freshness and amounts of MSG found in Chinese restaurants. In sum, not only did Lao Chu's call to arms fail to attract a significant following, but readers were also divided in their evaluation of Western fast food itself. The discussion, as in the Starbucks case (and in later stages of the McDonalds outrage), moved toward questions of taste. The question was no longer only whether consuming certain products was unpatriotic, but whether it was low-class, unhealthy, or culturally dissonant.

\section{It's hard to be highbrow}

Shortly after the Starbucks affair, two US-based business academics with previous experience in corporate communications in China advised multinational companies to 'encourage and even promote "confident nationalism" in the Chinese society' as a way to limit damage from nationalistic consumer actions (Wang \& Wang 2007). Some companies, including McDonalds, which before the 2008 Olympics used the slogan 'I'm loving it when China wins,' have begun doing so. It is far from clear whether issues other than national pride can serve as the basis of large-scale mobilization of Chinese consumers in the near future, but they do mark a departure from a nearly exclusive preoccupation with nationalism (and safety) and a shift towards concern with class. That such globalized means of distinguishing oneself from less modern or classy people as refusing to eat American fast food has finally reached the Chinese consuming class is of course by no means surprising. The question that must be asked is, rather, why the explicit articulation of highbrow eating has taken so long to appear.

For a country with such a strong cultural nationalist discourse as China's, it is remarkable that the kind of opposition to U.S. 'cultural imperialism,' strongly tinged 
with contempt for the 'uncultured American hicks,' that is seen in Europe, South America, or India, has been nearly absent. There is hardly any opposition to MTV, Hallmark, or Hollywood; indeed, former Chairman Jiang Zemin personally praised the film Titanic. Although a seminal volume for current Chinese nationalism bears the title China's Road in the Conspiracy of Globalization (Fang, Wang and Song 1999; see also Garver 2001), its principal author, Wang Xiaodong, has declared that 'development cannot be separated from globalization ... So no anti-globalization movement can form in China like that in Latin America' (Wang Xiaodong 2005). Unlike in other countries, the defense of Chinese tradition does not translate into a defense of 'high culture'perhaps because the opposition between 'high' and 'low' culture is weaker than elsewhere. Government-appointed guardians of culture have recently been more interested in securing favourable positions in the pop culture market than in suppressing it. From the Soviet operetta as the model for socialist music, there has been a logical progression to patriotic pop. The Propaganda Department and the General Administration of Press and Publications (GAPP) oversaw the compilation of a thousand 'healthy and optimistic' songs into a series of one hundred audio- and videotapes, VCDs and text booklets, called the All of China Sings Along Karaoke Song Pool (Zhonghua Dajia Chang kala OK quku), as early as 1991 (Xu Weicheng 1995). In the early 1990s, both GAPP and tourism authorities touted dance halls and karaoke halls as 'an important element of the masses' everyday cultural life' that had 'improved socialist structure (sic: shehuizhuyi jiegou), broadened the channels of knowledge transmission, enhanced the masses self-entertaining capacity (ziyu nengli), enriched society's cultural activities' (Xu Weicheng 1995). More recently, in 2005 and 2006, Taiwanese teenage heartthrob Jay Chou's songs 'The Snail' (Woniu) and 'Listen to Mummy' (Ting mama de hua) were included in a collection of songs approved for the patriotic education curriculum in Shanghai's secondary schools (Netease 2005). ${ }^{17}$

Chou has also been invited to take part in the mother of all official spectacles, China Central Television's Spring Festival Gala, a kind of yearly master narrative of national culture. ${ }^{18}$ In a recent article, the People's Daily unapologetically described the Galawhich combines a revolutionary and patriotic repertoire with disco-orchestrated pseudo-

\footnotetext{
${ }^{17}$ The official commendation pointed to the song's 'positive and progressive' lyrics, particularly the lines 'step by step, I inch upwards' and 'the tears and sweat I have shed,/one day I will have my own heaven.' ${ }^{18} \mathrm{http}: / / \mathrm{www}$.jayfan.com/ad.asp (accessed 2 April 2007). For an analysis of the Spring Festival Gala, see Sun (2002: 159-163) and Lu (2009).
} 
folk dances and pop songs — as a 'new folk celebration' that unites 100 million 'sons and daughters of China, no matter whether at home or abroad, to the north or south of the Great River,' and 'without any preaching, with plenty of inspirational force, naturally expresses $\ldots$ the spirit of the Party's $16^{\text {th }}$ Congress' through its songs and skits. The song 'Love of the Old Soil' (Gutu qing) 'transports the sons of China and millions of viewers into the great national sentiments, the great racial goals (guojia da qing, minzu da yi) of unifying the Fatherland, uniting the nation, developing the economy, and making the people happy' (Zhong Chengxiang 2003).

The causes of this official embrace of the lowbrow_or as Geremie Barmé calls it, this 'kowtowing to the vulgar' (1999: 281) — so different from the cultural politics of the Soviet Union or Eastern Europe under state socialism, need separate analysis. In any case, cultural chauvinism sits more comfortably with the lowbrow in China than in many other places, where cultural protectionism has tended to be a preserve of the high priests of high culture. In China, attempts to link a highbrow discourse of taste with cultural protectionism find less resonance with nationalists, and their effects are harder to predict. They can give rise to new, 'hip nationalist' narratives (Nyíri \& Zhang 2010; Dong \& Tian 2009), but they can also undermine accepted ones.

The recent proliferation of consumer boycotts, then, is part and parcel of the wave of popular nationalism that China is experiencing. As such, it is subject to the complex symbiosis between market and state in which the official discourse of the nation is coopted in commercial advertising and percolates down to Internet bulletin boards, while at the same time nationalist mobilization is subject to strict limits. Yet, though there is ample evidence for state manipulation and control of consumer nationalism, the boycotts discussed in this article have been grassroots movements. Although they reflect the prevailing mood of nationalism, they have nonetheless allowed the diversity of opinions normally restricted to online discussions spill briefly out to the streets. The politics of consumption are once again moving to the centre of Chinese nationalism; but they also provide an arena for emerging discourses of taste that allow individuals to sidestep or modify dominant versions of nationalism. 


\section{Reference List}

Adler, C. 2003, 'Colonel Sanders' March on China,' Time, 17 November.

Ai de zhongdian ('End of love'). 2008, 'Bali, ni da le ziji de erguang!' (Paris, You Slapped Your Own Face). Online, available: www.chinaren.com, 11 April. http://club.chinaren.com/120937688.html (accessed 28 April 2008).

Barmé, G. 1999, In the Red, Columbia University Press, New York.

Dong, L. \& Tian, K. 2009,. 'The Use of Western Brands in Asserting Chinese National Identity,' Journal of Consumer Research, no. 36, no page numbers.

EastSouthWestNorth. 2008. 'Daily Brief Comments April 11-20, 2008.' Online, available: http://zonaeuropa.com/200804b.brief.htm (accessed 28 April 2008).

Fang Ning, Wang Xiaodong \& Song Qiang (eds). 1999, Quanqiuhua yinmou xia de Zhongguo zhi lu (China's Road in the Globalization Conspiracy), Zhongguo Shehui Kexue Chubanshe, Beijing.

'Forbidden City Café.' 2007, China Daily, 24 September.

French, H. W. 2006, 'Online Throngs Impose a Stern Morality in China,' New York Times, 3 June.

Garver, J.W. 2001, 'More from the 'Say No Club,' The China Journal, no. 45, 152-58.

Gerth, K. 2003, China Made: Consumer Culture and the Creation of the Nation, Harvard University Press, Cambridge, MA.

Guangming Ribao. 2007a, 'You Xingbake kan wenwu huanjing de baohu' (Through Starbucks, Looking at the Protection of Cultural Monuments' Surroundings), 18 January. Online, available: http://news.sina.com.cn/o/2007-01-18/060511027554s.shtml (accessed 5 February 2007).

Guangming Ribao. 2007b, 'Zhuanjia jiaofeng "Xingbake kaijin Gugong," (Experts Discuss Forbidden City Starbucks), 18 January. Online, available: http://www.sina.com.cn/o/2007-0118/060511027555s.shtml (accessed 4 February 2007).

Han Han. 2008, 'Huida aiguozhe de wenti' (Answers to Patriots' Questions), 24 April. Online, available: http://bbs.book.sina.com.cn/tableforum/App/newreply.php?bbsid=9\&subid=0\&act=quote\&fid=31 2058\&replyid $=21481 \&$ ftitle $=\% \mathrm{BB} \% \mathrm{D} 8 \% \mathrm{~B} 4 \% \mathrm{~F} 0 \% \mathrm{~B} 0 \% \mathrm{AE} \% \mathrm{~B} 9 \% \mathrm{FA} \% \mathrm{D} 5 \% \mathrm{DF} \% \mathrm{~B} 5 \% \mathrm{C} 4 \% \mathrm{CE} \%$ $\mathrm{CA} \% \mathrm{CC} \% \mathrm{E} 2 \&$ tbid=3919\&jump=4 (accessed 29 April 2008).

Huashangbao. 2008, 'Gongshang bumen diaocha guiqi guanggao Maidanglao shou xunwen' (Industry and Trade Organs Investigated Begging Ad; Inquiry Targets McDonalds). Online, available: http://info.hotel.hc360.com/2005/06/21201545305.shtml (accessed 16 May 2006).

Jing, Jun. 2000, Feeding China's Little Emperors: Food, Children, and Social Change, Stanford University Press, Stanford.

Kafei. 2004, 'Zhongguo long 'hua' dao zai Libang qi xia, guoren paoxiao yaoqiu Libang Qi daoqian' (Chinese Dragon “Slides” on Nippon Lacquer; Our Countrymen Loudly Demand Nippon's Apology,' Jinlu Wanbao, 23 September. Online, available: http://news.tom.com/1006/20049231351387.html (accessed 16 May 2006).

Lao Chu. 2007, 'Kendeji, mo yakualiao Zhongguo wa' (KFC, You Can't Daunt the Chinese Baby), 7 March. Online, available:

http://www.tianya.cn/new/publicforum/content.asp?idarticle $=63298 \&$ stritem=no06\&idwriter $=1141$ 1235\&key=932756149\&flag=1 (accessed 7 March 2007).

Li Hongmei. 2008, 'Branding Chinese Products: Between Nationalism and Transnationalism,' International Journal of Communication, no. 2, 1125-63.

Li Yanjun. 2006, 'Ying le zunyan zhong le quantao' (Won Respect, Got into a Trap), Yingxiao Chuanqi. Online, available: http://www.cnyxcq.com/news (accessed 16 May 2006).

Lu, Xinyu. 2009, 'Ritual, Television, and State Ideology: Rereading CCTV's 2006 Spring Festival Gala,' in $T V$ China, (eds) C. Berry \& Ying Zhu, Indiana University Press, Bloomington, 111-128.

Mo Zhixu. 2008, 'Wo weishenme fandui dizhi' (Why I Oppose the Boycott), Zhongguo Xinwen Zhoukan, reproduced on Sina.com.cn, 23 April. Online, available: http://news.sina.com.cn/c/2008-0423/090815412541.shtml (accessed 2 May 2008).

Modern Weekly / Zhoumo Huabao. 2008. 'Ai, zeren yu gongxian' (Love, Responsibility, and Contribution) (advertisement), Lifestyle (Shenghuo) section, 12-13 July, C50.

Mu Rong Zhu Ning. 2007, 'Yelu shijie xuezhe bing bu quefa baorongxin' (Global Yale Scholar Does Not Lack a Sense of Inclusiveness), 17 January. Online, available: http://blog.sina.com.cn/u/4b28fe01010007n9 (accessed 20 January 2007).

Netease. 2005, 'Shanghai shi jiaowei jiaoyanshi yinyuejiao yanyuan Wang Yueping: Dui xuesheng you hen hao de jiaoyu yiyi' (Wang Yueping, Music Education Researcher at Shanghai Education Commission's Education Research Laboratory: It's Very Educational for Students), 15 March. Online, available: http://news.163.com/05/0315/05/1ES402QF0001122B.html (accessed 2 April 2007). 
Netease. 2007, 'Rui Chenggang, Xu Yongtao liao Gugong nei Xingbake quliu' (Rui Chenggang, Xu Yongtao Discuss Forbidden City Starbucks: Stay or Go?). Online, Available: http://news.163.com/07/0117/17/3529NVIU0001218K.html (accessed 20 January 2007).

Nyíri P. \& Zhang Juan, with M. Varrall. 2010, 'China’s Cosmopolitan Nationalists: "Heroes” and "Traitors” of the 2008 Olympics,' China Journal, no. 63, January.

People's Daily Online. 2000, 'Starbucks Cafe in Forbidden City Under Fire," 24 November. Online, available: http://english.people.com.cn/english/200011/24/eng20001124_56044.html (accessed 30 August 2009).

People's Daily Online. 2004a, '28 ri wangyou liuyan jingxuan: you sun guoge guoji guanggao panbieli he zai' (The Best Posts on the $28^{\text {th }}$ : How Can We Distinguish International Advertising That Harms National Dignity?), 28 September. Online, available: www.people.com.cn/GB/guandian/35534/2825369.html (accessed 16 May 2006).

People's Daily Online. 2004b, 'Libang qi, Fengtian, Naike yang guanggao weihe lao chu shier' (Why There is Always Trouble with Nippon Paint, Toyota and Nike). Online, available: www.people.com.cn/GB/14677/40606/3046692.html, (accessed 10 December 2006).

People's Daily Online. 2005, 'Maidanglao 'xiagui' guanggao yin bu man Zhengzhou chebo' (Zhengzhou Withdraws McDonalds "Kneeling” Commercial after Complaints). Online, available: http://info.hotel.hc360.com/2005/06/2114254277.shtml (accessed 16 May 2006).

Qin Xuan. 2008, 'LV gei 'Zangdu' juankuan le ma?' (Has LV Donated Money to “Tibetan independence"?') Zhongguo Xinwen Zhoukan, reproduced on Sina.com.cn, 23 April. Online, available: http://news.sina.com.cn/c/2008-04-23/090815412539.shtml (accessed 16 May 2006).

Rui Chenggang. 2007a, 'Bie rang xifang lajimen zai Zhongguo ganjue tai hao-Fasheng zai huaxuechang de yi mu' (Don't Let Western Trash Get Too Comfortable in China: A Scene at a Ski Resort), 8 January.

Rui Chenggang. 2007b, 'Qing Xingbake cong Gugong li chuqu' (Why Starbucks Needs to Get Out of the Forbidden City?), 12 January, http://blog.sina.com.cn/m/ruichenggang, accessed 20 January 2007.

Rui Chenggang. 2007c, 'Xingbake quanqiu zongzai jian CEO gei wo de huixin' (Starbucks Global Chairman and CEO's Reply to Me), 14 January. Online, available: http://blog.sina.com.cn/m/ruichenggang (accessed 20 January 2007).

Rui Chenggang. 2007d, 'Wo daodi xiang ganma?' (What Am I Actually After?), 19 January. Online, available: http://blog.sina.com.cn/m/ruichenggang (accessed 20 January 2007).

Rui Chenggang. 2007e, 'Hexie wei dao' (Harmony is the Way), 20 January. Online, available: http://blog.sina.com.cn/m/ruichenggang (accessed 20 January 2007).

Sina.com.cn. 2007, 'Yang Chenglin zai yu wangyou dizhi; daiyan Maidanglao guanggao bei shanchu' (Yang Chenglin Runs into Netizen Boycott Again; McDonalds Spokesman Ad Cancelled,' 24 January. Online, available: http://ent.sina.com.cn/s/h/2007-01-24/08101423338.html (accessed 24 January 2007).

Sina.com.cn. 2008, 'Jialefu yin dizhi tuihuo, bentu gongyingshang shou qianlian' (Carrefour Returns Goods Because of Boycott; Local Suppliers Affected), 26 April. Online, available: http://www.sina.com.cn (accessed 28 April 2008).

Sitai. 2008, 'Geren dui dizhi huodong de yixie kanfa' (Some Personal Opinions on the Boycott), 17 April. Online, available: http://my1510.cn/article.php?73a815b678cf6d3c (accessed 3 May 2008).

Sun Wanning. 2002, Leaving China: Media, Migration, and the Transnational Imagination, Rowman \& Littlefield, Lanham.

Tan Renwei \& Youtian. 2008, 'Dizhi xiang 'neihong'? Bai Yansong fandui dizhi Jialefu,' (Is the Boycott Like Unrest? Bai Yansong Opposes Carrefour Boycott), People’s Daily Online, 16 April. Online, available: http://bbs.people.com.cn/postDetail.do?view=1\&id=85397347\&bid=43 (accessed 4 May 2008).

Tang Rong. 2008, 'Qingxu yangai xia de zhuyi zhi zheng' (Under the Cover of Emotions, A Battle of Ideologies), Xin Shiji Zhoukan, 28 April. Online, available: http://news.sina.com.cn/c/2008-0428/140615443765 (accessed 3 May 2008).

Tang Rong \& Chen Xuan. 2008, 'Yi chang chaohu xiangxiang de dizhi' (A Boycott Beyond Expectations), Xin Shiji Zhoukan, 28 April. Online, available: http://news.sina.com.cn/c/2008-0428/140615443764.shtml (accessed 2 May 2008).

Tianya. 2007. 'Yang Chenglin daiyan Maidanglao, wan ren qianming ju chi!' (Yang Chenglin as McDonalds Spokeswoman: Gather Ten Thousand Signatures for a Boycott!), 4 January. Online, available: http://cache.tianya.cn/publicforum/Content/funinfo/1/285579.shtml (accessed 27 January 2007).

Wang Guanghui. 2005, 'Beijing diaocha Baojie shexian weifa guanggao, jiaoting Maidanglao guanggao' (Beijing Investigates P\&G Ad Accused of Violating Laws, Calls for Stop of McDonalds Ad), 
Beijing Qingnianbao, 25 June.

Wang, Jian. 2006, 'The Politics of Goods: A Case Study of Consumer Nationalism and Media Discourse in Contemporary China,' Asian Journal of Communication, vol. 16, no. 2: 187-206.

Wang, Jian \& Zhiying Wang. 2007, 'The Political Symbolism of Business. Exploring Consumer Nationalism and its Implications for Corporate Reputation Management in China,' Journal of Communication Management, vol. 11, no. 2, 134-49.

Wang Xiaodong. 2005, 'Chinese Nationalism Under the Shadow of Globalization,' speech at the London School of Economics and Political Science, 7 February.

Watts, J. 2007, 'Starbucks Faces Eviction from the Forbidden City,' The Guardian, 18 January.

Xinhua. 2004, “"Badao” qiche guanggao re zhong nu Fengtian xiang wo guo xiaofeizhe zhiqian' (Prado Car Ad Provokes Mass Anger; Toyota Apologises to Our Country's Customers), 23 September. Online, available: http://news.tom.com/1006/2004923-1351626.html (accessed 16 May 2006).

Xinhuanet. 2008, 'Jiang Yu: Fafang ying dui Zhongguo minzhong yijian he qingxu jinxing fansi' (Jiang Yu: French Side Should Think about Opinion and Emotions of Chinese Masses), 15 April. Online, available: http://news.xinhuanet.com/newscenter/2008-04/15/content_7981786.htm (accessed 2 May 2008).

Xin Jing Bao. 2007, 'Yi lixing taidu kandai Gugong Xingbake' (Looking Rationally at the Forbidden City Starbucks), 17 january. Online, available: http://news.sina.com.cn/c/pl/2007-0117/091712059724.shtml (accessed 4 February 2007).

$\mathrm{Xu}$ Weicheng. 1995, Speech at the National Audiovisual Publishing Work Conference, 21 December, in 'Guanyu yinfa Xu Weicheng, Yu Youxian tongzhi zai Quanguo yinxiang chuban gongzuo Huiyi shang jianghua de tongzhi' (Notice on the Printing and Distribution of the Speeches of Comrades $\mathrm{Xu}$ Weicheng and Yu Youxian at the National Audiovisual Publishing Work Conference), General Administration of Press and Publication document [1996], 121.

Yang Lili. 2004, 'Libang Qichan guanggao zhong “panlong hualuo” huamian yinqi zhengyi' ('Sliding Dragon’ Frame in Libang Lacquer Factory Ad Triggers Controversy), reproduced on news.tom.com from Beijing Chenbao, 23 September. Online, available: http://news.tom.com/4005/4411/4413/20040923-1349567.html (accessed 16 May 2006).

Zhang Xiong \& Chen Xuan. 2008, 'Zhongguoshi fennu: yi chang chaohu xiangxiang de dizhi' (Rage Chinese Style: A Boycott that Exceeded Expectations), Xin Shiji Zhoukan, reproduced on Sina.com.cn, 28 April. Online, available: Http://news.sina.com.cn/c/2008-0428/140615443763.shtml (accessed 4 May 2008).

Zhao, Suisheng. 2008, 'The Olympics and Chinese Nationalism,' China Security, vol. 4, no. 3, 48-57.

Zhong Chengxiang. 2003, 'Xin de minzu qingdian, mei de wenhua da can' (A New Folk Celebration, A Beautiful Cultural Feast), Renmin Ribao, 11 February, 14.

Zhongguo Xinwen Zhoukan. 2008, 'Weishenme dizhi Jialefu' (Why Boycott Carrefour), 23 April. Online, available: http://news.sina.com.cn/c/2008-04-23/090815412532.shtml (accessed 2 May 2008).

Zhou Qing'an. 2007, 'Xingbake neng fou banchu Zhongguoren xinling de Gugong' (Can Starbucks Move Out of the Forbidden City in Chinese People's Minds?), Nanfang Dushibao, 17 January. Online, available: http://www.sina.com.cn/c/p1/2007-01-17/090012059215.shtml (accessed 4 February 2007). 